\title{
Synthesis of Poly(ethyl acrylate) by Single Electron Transfer-Degenerative Chain Transfer Living Radical Polymerization in Water Catalyzed by $\mathrm{Na}_{2} \mathrm{~S}_{2} \mathrm{O}_{4}$
}

\author{
JORGE F. J. COELHO, ${ }^{1,2}$ ERICA Y. CARVALHO, ${ }^{1}$ DINA S. MARQUES, ${ }^{1}$ ANATOLIY V. POPOV, ${ }^{3}$ \\ VIRGIL PERCEC, ${ }^{4}$ PEDRO M. F. O. GONÇALVES, ${ }^{2}$ M. H. GIL ${ }^{1}$ \\ ${ }^{1}$ Chemical Engineering Department, University of Coimbra, Pólo II, Pinhal de Marrocos, 3030-290 Coimbra, Portugal \\ ${ }^{2}$ CIRES SA - Companhia Industrial de Resinas Sintéticas, Apartado 20, Samoqueiro - Avanca, 3864-752 Estarreja, Portugal \\ ${ }^{3}$ Department of Radiology, University of Pennsylvania, Philadelphia, Pennsylvania 19104-6323 \\ ${ }^{4}$ Roy and Diana Vagelos Laboratories, Department of Chemistry, University of Pennsylvania, Philadelphia, \\ Pennsylvania 19104-6323
}

Received 20 July 2007; accepted 18 September 2007

DOI: 10.1002 / pola.22393

Published online in Wiley InterScience (www.interscience.wiley.com).

\begin{abstract}
Living radical polymerization of ethyl acrylate was achieved by single-electron-transfer/degenerative-chain transfer mediated living radical polymerization in water catalyzed by sodium dithionite. The plots of number-average molecular weight versus conversion and $\ln [\mathrm{M}]_{0} /[\mathrm{M}]$ versus time are linear, indicating a controlled polymerization. This method leads to the preparation of $\alpha, \omega$-di(iodo)poly(ethyl acrylate) $(\alpha, \omega$-di(iodo)PEtA) macroinitiator that can be further functionalized. The molecular weight distributions were determined using a combination of three detectors (TriSEC): right-angle light scattering, a differential viscometer and refractive index. The method studied in this work represents a possible route to prepare well-tailored macromolecules made of ethyl acrylate in environmental friendly reaction medium. To the best of our knowledge there is no previous report dealing with the synthesis of PEtA by any LRP approach in aqueous medium. Furthermore, the method described in this article was successfully applied in pilot scale reactions under industrial production conditions. (C) 2007 Wiley Periodicals, Inc. J Polym Sci Part A: Polym Chem 46: 421-432, 2008
\end{abstract}

Keywords: degenerative transfer; ethyl acrylate; kinetics; living polymerization; poly(ethyl acrylate); single electron transfer; tacticity; telechelics

\section{INTRODUCTION}

Living Radical Polymerization is one of most powerful tools to prepare well tailored architectures that fit emerging applications. This strategy combines the exceptional flexibility and

Correspondence to: J. F. J. Coelho (E-mail: jcoelho3@ eq.uc.pt)

Journal of Polymer Science: Part A: Polymer Chemistry, Vol. 46, 421-432 (2008) ○ 2007 Wiley Periodicals, Inc. potential of the living approaches with the radical polymerization advantages. The most common strategies include reversible addition fragmentation chain transfer (RAFT) ${ }^{1}$ nitroxide-mediated living radical polymerization (NMP) ${ }^{2}$ and metalcatalyzed living radical polymerization. ${ }^{3}$ Because of the remarkable interest from the academia and industrial world, the different methods have witnessed important developments over the last decade. The reaction conditions become more attractive and easy to perform in the industrial 
environment. On this matter, the development of a new strategy based on reversible activationdeactivation step required to accomplish LRP by combination of competitive single-electron-transfer (SET) and degenerative-chain transfer ${ }^{4}$ is a clear example. Discovered by Percec, Popov and coworkers, ${ }^{4-6}$ this strategy has proved to be effective in the polymerization of activated ${ }^{7-9}$ and non-activated monomers. ${ }^{4-6,8-11}$

The incorporation of acrylic based polymers was commonly used to the rubber toughening of glassy polymers, exerting their modifying influence in improving the toughness of the blended systems. ${ }^{12}$ The acrylic monomers are particularly useful to tailor the properties of other materials due to their characteristics, such as water repellence ${ }^{13}$ good filmability, ${ }^{13}$ transparency ${ }^{13}$ chemical resistance, and low cost. There are several strategies reported to incorporate PEtA segments, such as blending, ${ }^{12,14}$ grafting, ${ }^{13}$ and radical copolymerization. ${ }^{15,16}$ The main problems associated to the above approaches are concerned to the lack of control over the final macrostructures that typically depend on the relative amount of monomers used and reactivities. For that reasons, the strategies that allow the preparation of telechelic polymers are highly demanded.

Regarding the synthesis of PEtA via a living route there is little information available in the literature. Wu et al. ${ }^{17}$ synthesized star-shaped polymer (polystyrene) $)_{n}$-[poly(ethyl acrylate $)_{m}$ ] from a hydrobrominated PS macroinitiator via atom transfer radical polymerization (ATRP) in toluene at $90{ }^{\circ} \mathrm{C}$. Shi ${ }^{18}$ proposed the synthesis of diblock copolymers PS-b-PEtA from a PS macroinitiator with an active bromine in the $\omega$-end of the chain by ATRP at $90{ }^{\circ} \mathrm{C}$. Jianying ${ }^{19}$ studied the random copolymerization of styrene and ethyl acrylate at $125{ }^{\circ} \mathrm{C}$ using TEMPO as a mediator. Finally, the PEtA was also prepared by $\operatorname{ATRP}^{20}$ at $90{ }^{\circ} \mathrm{C}$ following a procedure developed for other vinylic monomers ${ }^{21}$ several years ago. The rigorous reaction conditions used to prepare the macroinitiator and final structures are incompatible with any attempt to prepare those structures in large scale.

The aim of the present work is to study the synthesis of PEtA by single electron transfer-degenerative chain transfer mediated living radical polymerization (SET-DTLRP) in water. To the best of our knowledge there are no reports about synthesis of $\alpha, \omega$-di(iodo)PEtA macroinitiators in aqueous medium that can be further modified.
The modification and functionalization of the polyacrylate macroinitiators is extremely useful, aiming to the formation of new families of materials with improved properties. Moreover, the synthesis of polymers containing segmented blocks has noticed an increasing attention from both scientific and technological points of view. ${ }^{16}$ From the mechanistic standpoint, the possibility of synthesizing an acrylate with short alkyl chain in aqueous medium is also extremely interesting due to low steric stabilization resonance expected from the short alkyl side chain over the iodine dormant species.

The SET-DTLRP approach have presented promising results in its industrial implementation, leading to flexible materials that are able to replace some commercial products that are made from a thermoplastic blended with free plasticizers, ${ }^{11,22-24}$ being foreseeable in its commercialization, in large production in short time period. The development and improvement of methods that involve commercially available compounds at the same time inexpensive and easy to handle is extremely important to foresee the industrial implementation of the LRP processes. Preliminary experiments leading to the activation of the $\alpha, \omega$-di(iodo) chain ends were successfully carried out. The polymer solutions in THF were also characterized by multi-detector size chromatography (TriSEC), determining by this way the relationship between the intrinsic viscosity versus molecular weight and radius of gyration versus molecular weight.

\section{EXPERIMENTAL}

\section{Materials}

THF HPLC-grade uninhibited, basic alumina, iodoform (99\%), sodium dithionite (85\%), sodium bicarbonate (99\%), and EtA were purchased from Sigma-Aldrich. EtA was purified through a basic $\mathrm{Al}_{2} \mathrm{O}_{3}$ column just before polymerization. $p$-Toluenesulfinic acid, sodium salt, hydrate (pTsNa; 98\%) was purchased form Acros Organics. The Polystyrene standards for TriSEC measurements were purchased from Polymer Laboratories. Poly (vinyl alcohol) (PVA) (average $M_{\mathrm{w}} \quad 85,000-$ 124,$000 ; 87-89 \%$ hydrolyzed) was purchased from Sigma-Aldrich. Hydroxypropyl methylcellulose-Methocel F50 (MF50) was purchased from Dow Chemical Company. The other compounds 
Table 1. Molar Ratios of Reagents and Amounts of Surfactants and Water Studied in the Kinetic Experiments Carried Out by SET-DTLRP

\begin{tabular}{ccccccccc}
\hline No. & EtA & $\mathrm{CHI}_{3}$ & $\mathrm{Na}_{2} \mathrm{~S}_{2} \mathrm{O}_{4}$ & $\mathrm{NaHCO}_{3}$ & pTsNa & PVA88 & MF50 & $\mathrm{H}_{2} \mathrm{O}$ \\
\hline & mol & mol & $\mathrm{mol}$ & mol & mol & ppm & ppm & $\mathrm{mL}$ \\
1 & 100 & 1 & 4 & 1.45 & 2 & 490 & 210 & 9 \\
2 & 250 & 1 & 4 & 1.45 & 2 & 490 & 210 & 9 \\
3 & 500 & 1 & 4 & 1.45 & 2 & 490 & 210 & 9 \\
4 & 1000 & 1 & 4 & 1.45 & 2 & 490 & 210 & 9 \\
\hline
\end{tabular}

were ordered from Sigma-Aldrich and used as received.

\section{Polymerization of EtA via SET/DTLRP}

The typical procedure was performed as described (example ratio $[\mathrm{EtA}]_{0} /\left[\mathrm{CHI}_{3}\right]_{0}=100$ ). A $50 \mathrm{~mL}$ Ace Glass $8645 \# 15$ pressure tube equipped with bushing and plunger valve was charged with $9 \mathrm{~mL}$ of deionized water, $48.3 \mathrm{mg}$ of a $3 \%$ PVA solution (490 ppm), and $33.4 \mathrm{mg}$ of a $1.86 \%$ MF50 solution $(210 \mathrm{ppm})$. The content was stirred and bubbled with nitrogen for $10 \mathrm{~min}$. Then other compounds were added: catalyst $\left(\mathrm{Na}_{2} \mathrm{~S}_{2} \mathrm{O}_{4}, 191.57 \mathrm{mg}, 1.10 \mathrm{mmol}\right)$, initiator $\left(\mathrm{CHI}_{3}, 108.30 \mathrm{mg}, 0.28 \mathrm{mmol}\right)$, buffer $\left(\mathrm{NaHCO}_{3}\right.$, $33.51 \mathrm{mg}, 0.40 \mathrm{mmol}$ ), additive (pTsNa, $107.94 \mathrm{mg}$, $0.55 \mathrm{mmol})$ and EtA $(3 \mathrm{~mL}, 27.75 \mathrm{mmol})$. The tube was closed, frozen in $\mathrm{MeOH} /$ dry ice and degassed through the plunger valve by applying cycles of reduced pressure followed by filling the tube with inert gas for 20 times at $-40{ }^{\circ} \mathrm{C}$. The valve was closed and the reaction was kept in a water bath for $1 \mathrm{~h}$ at $35{ }^{\circ} \mathrm{C}$ agitated with a magnetic stirring bar. At the end of the reaction, a small aliquot was taken for TriSEC measurements. The polymer was placed in a preweighted vial and the remaining part of the tube was carefully washed with THF and placed in a different vial. After drying in a vacuum oven until the weight was constant, both vials were weighted to determine the final conversion $(68 \%)$.

\section{Characterization Techniques}

The chromatography parameters of the samples were determined using a HPSEC, Viscotek (Dual detector 270, Viscotek, Houston, USA) with a differential viscosimetry (DV), right angle laser light-scattering (RALLS; Viscotek), and RI (Knauer K-2301). The column set consisted of a PL $10 \mu \mathrm{m}$ guard column $(50 \mathrm{~mm} \times 7.5 \mathrm{~mm})$ followed by two MIXED-B PL columns (300 mm $\times 7.5 \mathrm{~mm}, 10 \mu \mathrm{m})$. HPLC pump (Knauer K-1001) was set with a flow rate of $1 \mathrm{~mL} / \mathrm{min}$. The eluent (THF) was previously filtered through a $0.2 \mu \mathrm{m}$ filter. The system was also equipped with a Knauer on-line degasser. The tests were done at $30{ }^{\circ} \mathrm{C}$ using an Elder CH-150 heater. Before the injection $(100 \mu \mathrm{L})$, the samples were filtered through a PTFE membrane with $0.2 \mu \mathrm{m}$ pore. The system was calibrated with narrow polystyrene standards. The differential refractive index of PEtA for $670 \mathrm{~nm}$ was determined $(\mathrm{dn} / \mathrm{dc}=0.061)$. The analysis of light scattering data by Viscotek's software was done assuming that the second virial coefficient was zero, considering the low solution concentrations used in this work. The ${ }^{1} \mathrm{H}$ NMR spectra $(500 \mathrm{MHz})$ were recorded in a Bruker DRX 500 spectrometer at $32{ }^{\circ} \mathrm{C}$ in $\mathrm{CDCl}_{3}$ with tetramethylsilane as internal standard. Diad tacticities of the polymer were determined from ${ }^{1} \mathrm{H}$ NMR as it was described elsewhere. ${ }^{25}$ Dynamical mechanical thermal analysis (DMTA) of thick specimens $(15.20 \mathrm{~mm} \times 7.45 \mathrm{~mm} \times 1.20 \mathrm{~mm})$ were performed using a Triton Tritec 2000 in the constrain layer damping mode using two frequencies $(1 \mathrm{~Hz}$ and $10 \mathrm{~Hz})$, with a standard heating rate of $2{ }^{\circ} \mathrm{C} \min ^{-1}$. The $T_{\mathrm{g}}$ was determined as the peak in $\tan \delta\left(\operatorname{Tan} \delta=\mathrm{E}^{\prime \prime} / \mathrm{E}^{\prime}\right)$ where $\mathrm{E}^{\prime \prime}$ and $\mathrm{E}^{\prime}$ are the loss and storage modulus, respectively.

\section{RESULTS AND DISCUSSION}

The kinetics experiments carried out in this work are summarized in Table 1.

The points in the kinetics shown in Figure 1 were obtained gravimetrically according to the procedure described (vide infra).

Figure 1(a) shows the kinetic plots for $\mathrm{Na}_{2} \mathrm{~S}_{2} \mathrm{O}_{4} / \mathrm{NaHCO}_{3}$-catalyzed LRP of EtA at $35{ }^{\circ} \mathrm{C}$ for DP $=100$. The PVA 88 and MF50 were used as suspending agents to stabilize the ethyl acrylate droplets. 
a)
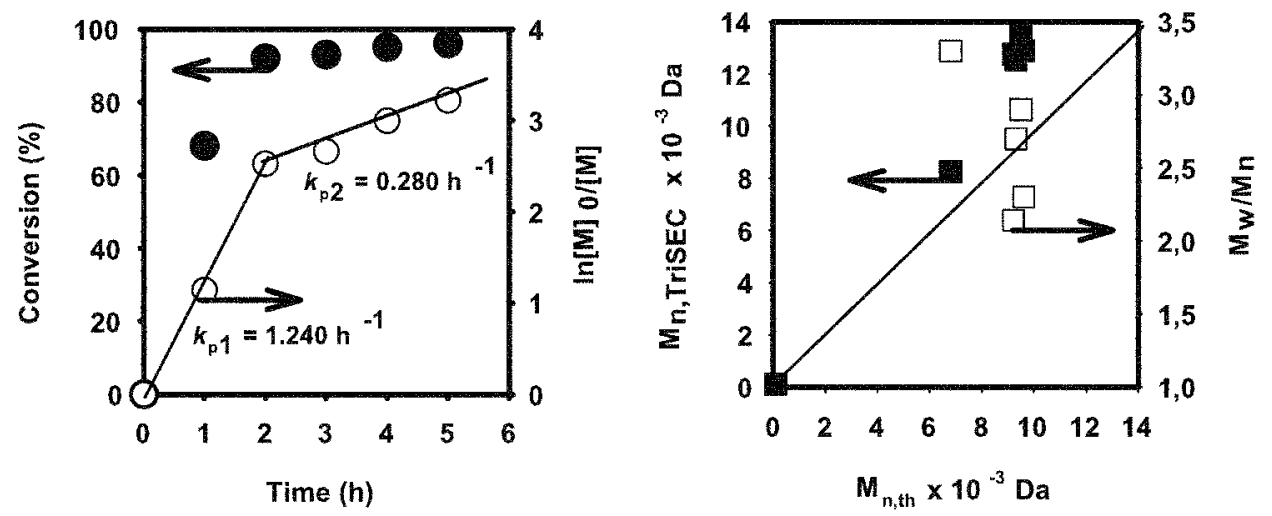

b)
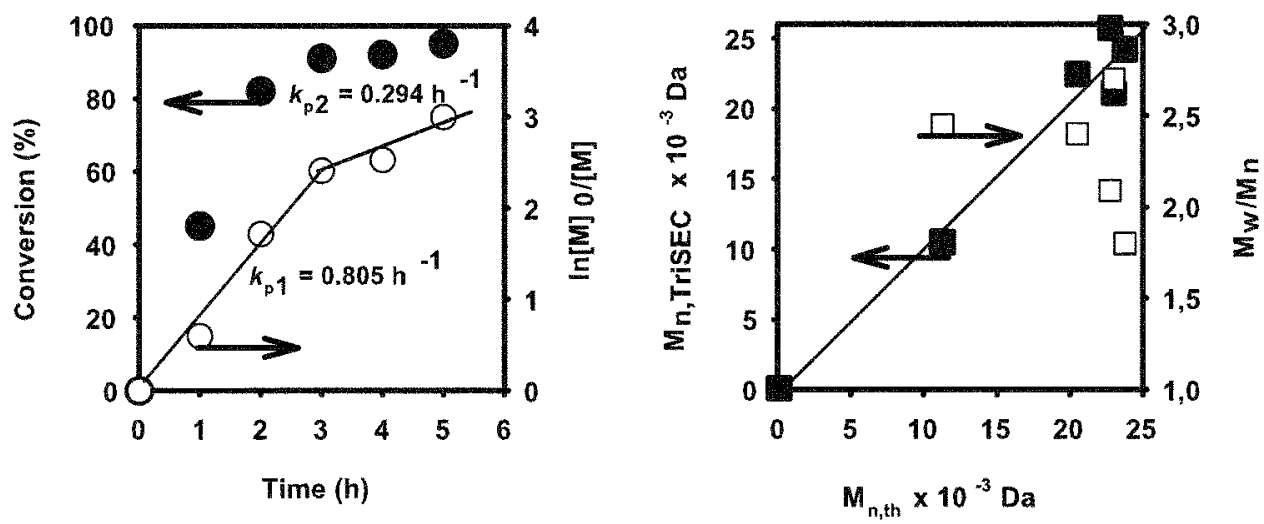

Figure 1. $\mathrm{Na}_{2} \mathrm{~S}_{2} \mathrm{O}_{4} / \mathrm{NaHCO}_{3}$-catalyzed LRP of EtA initiated with iodoform in $\mathrm{H}_{2} \mathrm{O}$ in the presence of SA Methocel F50 and PVA 88, $[\mathrm{EtA}]_{0} /\left[\mathrm{H}_{2} \mathrm{O}\right]_{0}=1 / 3(\mathrm{v} / \mathrm{v}):$ (a) $[\mathrm{EtA}]_{0} /$ $\left[\mathrm{CHI}_{3}\right]_{0} /\left[\mathrm{Na}_{2} \mathrm{~S}_{2} \mathrm{O}_{4}\right]_{0} /[\mathrm{pTsNa}]_{0} /\left[\mathrm{NaHCO}_{3}\right]_{0}=100 / 1 / 4 / 2 / 1.45(\mathrm{~mol} / \mathrm{mol} / \mathrm{mol} / \mathrm{mol}) ;[\mathrm{Metho}-$ celF50]/[PVA 88] $=210 / 490(\mathrm{ppm} / \mathrm{ppm}, \mathrm{w} / \mathrm{w}$ relative to EtA $), 35{ }^{\circ} \mathrm{C}$; (b) $[\mathrm{EtA}]_{0} /\left[\mathrm{CHI}_{3}\right]_{0} /$ $\left[\mathrm{Na}_{2} \mathrm{~S}_{2} \mathrm{O}_{4}\right]_{0} /[\mathrm{pTsNa}]_{0} /\left[\mathrm{NaHCO}_{3}\right]_{0}=250 / 1 / 4 / 2 / 1.45(\mathrm{~mol} / \mathrm{mol} / \mathrm{mol} / \mathrm{mol}) ;[$ [Methocel F50]/ $[\mathrm{PVA} 88]=210 / 490(\mathrm{ppm} / \mathrm{ppm}, \mathrm{w} / \mathrm{w}$ relative to EtA $), 35^{\circ} \mathrm{C}$.

The kinetic data exhibit two different slopes on the $\ln [\mathrm{M}]_{0} /[\mathrm{M}]$ versus polymerization time. The first slope $k_{\mathrm{p} 1}=1.24 \mathrm{~h}^{-1}$ represents the region where monomer diffusion is not limited by the viscosity of the reaction mixture. Because of the increase of conversion the reaction medium becomes more viscous and eventually leads to the formation of a solid phase. This process leads to the appearance of a second stage that presents a kinetic constant $\left(k_{\mathrm{p} 2}\right)$ several times lower than $k_{\mathrm{p} 1}$. The described trend was also observed in the cases of SET-DTLRP of other monomers such as vinyl chloride, ${ }^{4-6,9,26}$ 2-ethylhexyl acrylate, ${ }^{9}$ tert-butyl acrylate, ${ }^{9}$ and butyl acrylate. ${ }^{8}$ The results presented in Figure 2, for DP $=500$ and $\mathrm{DP}=1000$ show only one kinetic constant, contrarily to the results observed for $\mathrm{DP}=100$ and
$\mathrm{DP}=250$. The reason for this result is not fully understood at the moment. However, such observation could be related to slower reaction during the first hours of polymerization, which leads to a slower increase of viscosity inside the droplet that is known to decrease the reaction rate.

The termination reactions can be neglected, since the kinetic results show a first-order kinetic of the reaction relatively to the monomer concentration. Such behavior is observed for the kinetics presented in this article regardless the ratio [monomer $]_{0} /[\text { initiator }]_{0}$ considered (Figs. 1 and 2). Furthermore, the results suggest a linear dependence of the molecular weight determined by TriSEC $\left(M_{n, \text { TriSEC }}\right)$ versus the theoretical molecular weight $\left(M_{n, \text { th }}\right)$. These two features of the SETDTLRP of EtA support the living polymerization Journal of Polymer Science: Part A: Polymer Chemistry DOI 10.1002/pola 
a)
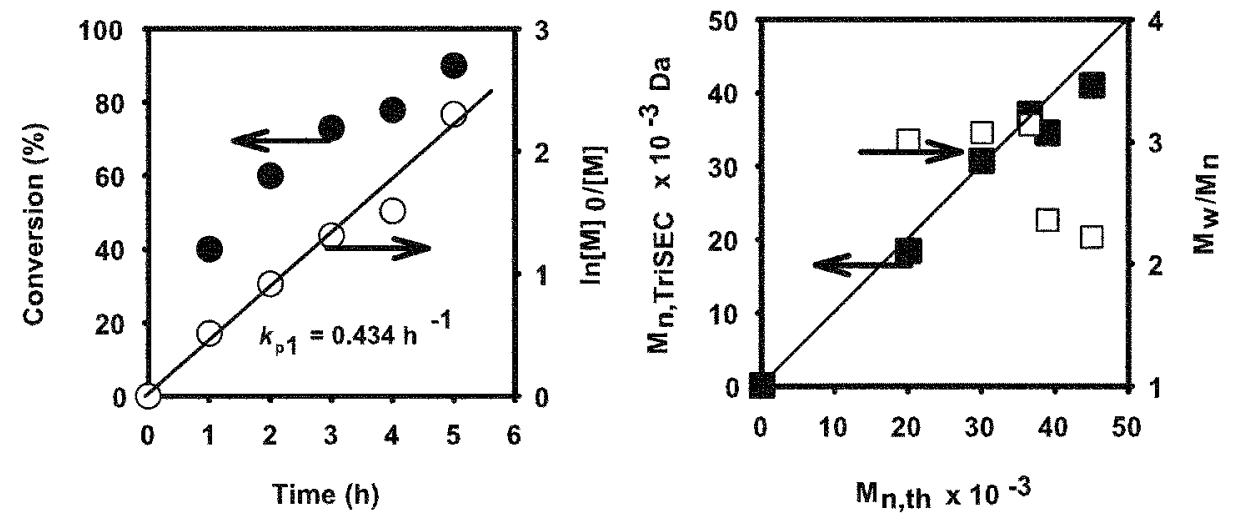

b)
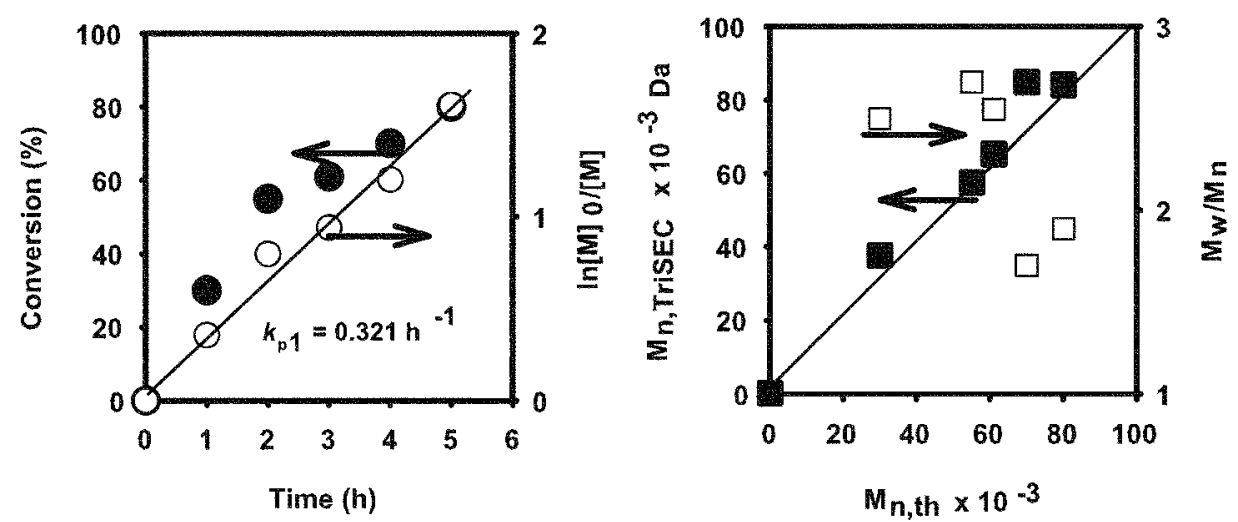

Figure 2. $\mathrm{Na}_{2} \mathrm{~S}_{2} \mathrm{O}_{4} / \mathrm{NaHCO}_{3}$-catalyzed LRP of EtA initiated with iodoform in $\mathrm{H}_{2} \mathrm{O}$ in the presence of SA Methocel F50 and PVA 88, (a) $[\mathrm{EtA}]_{0} /\left[\mathrm{CHI}_{3}\right]_{0} /\left[\mathrm{Na}_{2} \mathrm{~S}_{2} \mathrm{O}_{4}\right]_{0} /[\mathrm{pTsNa}]_{0} /$ $\left[\mathrm{NaHCO}_{3}\right]_{0}=1000 / 1 / 4 / 2 / 1.45(\mathrm{~mol} / \mathrm{mol} / \mathrm{mol} / \mathrm{mol}) ;$ [Methocel F50]/[PVA 88] = 210/490 (ppm/ppm, w/w relative to EtA), $35{ }^{\circ} \mathrm{C}$; (b) $[\mathrm{EtA}]_{0} /\left[\mathrm{CHI}_{3}\right]_{0} /\left[\mathrm{Na}_{2} \mathrm{~S}_{2} \mathrm{O}_{4}\right]_{0} / /[\mathrm{pTsNa}]_{0} /$ $\left[\mathrm{NaHCO}_{3}\right]_{0}=1000 / 1 / 4 / 2 / 1.45(\mathrm{~mol} / \mathrm{mol} / \mathrm{mol} / \mathrm{mol}) ;[$ Methocel F50] $/[\mathrm{PVA} 88]=210 / 490$ ( $\mathrm{ppm} / \mathrm{ppm}, \mathrm{w} / \mathrm{w}$ relative to EtA), $35^{\circ} \mathrm{C}$.

mechanism. As expected, the reaction rate decreases with the ratio monomer/initiator because of a reduced number of radicals for high DPs.

According to the other results reported in the literature for SET-DTLRP systems ${ }^{8,9}$ the polydispersity is relatively high and is justified by the heterogeneity of the medium.

The low polydispersity is not necessarily resulted from the living polymerization, as described in the literature. ${ }^{26,27}$ The living system only requires the absence of any chain-breaking reaction. To obtain a polymer with a narrow molar mass distribution, it is necessary to fulfil various requirements that are specific for each polymerization system. Several studies have been carried out on this subject, thus identifying five major conditions: ${ }^{28-30}$ (1) chain transfer or termination should be negligible; (2) the rate of propagation should be higher than the rate of depropagation; (3) the rate of initiation should be as fast as the rate of propagation; (4) the equilibrium created between the different species involved in the reaction that also have different reactivities should be fast; and (5) the system should be homogeneous with a vigorous agitation.

Under the conditions mentioned, the polydispersity $M_{\mathrm{w}} / M_{n}$ should decrease with conversion. When it increases, it is possible to identify the presence of chain breaking reactions. Living systems are not synonym as "with low polydispersity." The last requirement for low polydispersity described above, mostly related to the homogeneity of the system is impossible to achieve for EtA 
polymerization when water is used as continuous phase. The balance in this case will be always between a friendly reaction medium or the degree of control over the molecular weight distribution. Therefore, for industrial large scale production the desirable condition is to employ the water as continuous phase. Moreover, the industry is used to deal with polymers with high polydispersity for decades that were prepared by conventional radical processes. ${ }^{31}$ Apart from this, the polymers obtained by iodine transfer living polymerization even in homogeneous systems possess polydidispersity around 2. Iodine transfer (degenerative transfer) is a part of the SET-DTLRP mechanism (vide infra). ${ }^{32,33}$

\section{Structural Analysis of the PEtA by $500 \mathrm{MHz}$ ${ }^{1} \mathrm{H}-\mathrm{NMR}$ Spectroscopy}

Figure 3 shows the ${ }^{1} \mathrm{H}$ NMR spectra of the PEtA with $M_{n, \text { TriSEC }}=8000 \mathrm{Da}$ [Fig. 3(a)] and 14,000 Da [Fig. 3(b)] prepared by SET-DTLRP at $35^{\circ} \mathrm{C}$. The resonancing protons are labelled by italic. While the spectrum (a) reveals the resonances of two active chain ends: namely, a terminal iodoform residue $-\mathrm{CHI}_{2}-$ at $5.0 \mathrm{ppm},{ }^{5,6,34}$ and $-\mathrm{CHI}-\mathrm{C}(\mathrm{O}) \mathrm{OEt}$ at $4.25 \mathrm{ppm},{ }^{35}$ the spectrum $(\mathrm{b})$ demonstrates only the signal of one active chain

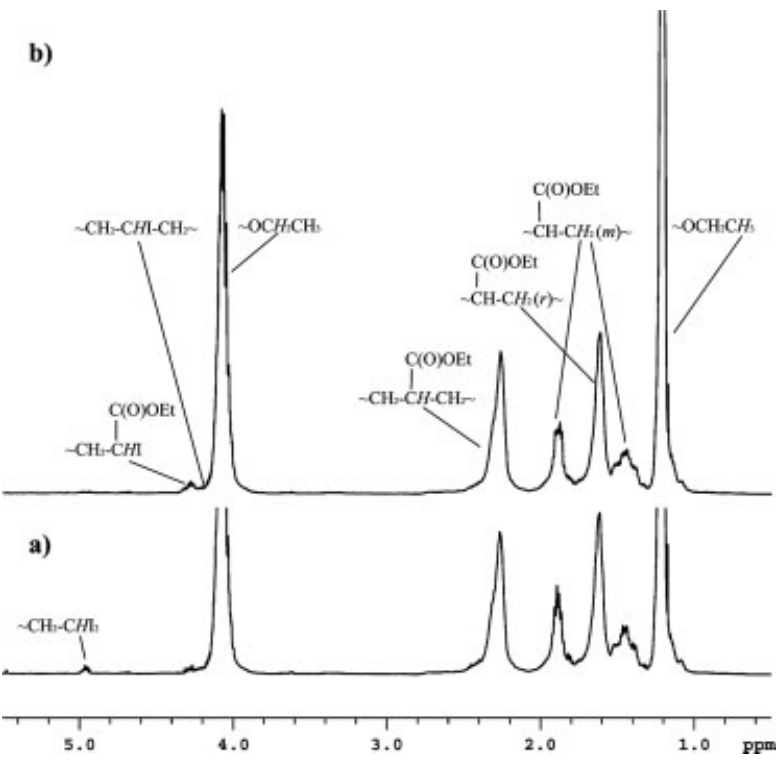

Figure 3. $500 \mathrm{MHz}^{1} \mathrm{H} \mathrm{NMR}$ spectra in $\mathrm{CDCl}_{3}$ of $\alpha, \omega$ di(iodo) PEtA obtained by SET-DTLRP in water at $35{ }^{\circ} \mathrm{C}$; (a) $M_{n, \text { TriSEC }}=8,000 \mathrm{Da}$; (b) $M_{n, \text { TriSEC }}=14,000$ Da. end $-\mathrm{CHI}-\mathrm{C}(\mathrm{O}) \mathrm{OEt}$ at $4.25 \mathrm{ppm}$. By this means that a low molecular weight PEtA $(\leq 8000 \mathrm{Da})$ represents a mixture of one- and two-side growing polymer chains. Eventually all $-\mathrm{CHI}_{2}$ end groups enter into the reaction (via SET or DT mechanisms, eqs 6 and 7, Scheme 1) and PEtA with molecular weight $\geq 14,000 \mathrm{Da}$ is already a two-side growing polymer. The small signal of an internal iodoform residue $-\mathrm{CH}_{2} \mathrm{CHI}-\mathrm{CH}_{2}-$ is hidden inside a strong signal of the methylene of ethoxy group $-\mathrm{OCH}_{2}-$ at $4.05 \mathrm{ppm} .{ }^{35}$ Methyl protons of $-\mathrm{OCH}_{2} \mathrm{CH}_{3}$ group signal at $1.2 \mathrm{ppm}$. The assignment of main chain signals and tacticity measurement was maid according to those for poly(butyl acrylate) by Tabuchi et al., ${ }^{25}$ The methine group resonances at $2.25 \mathrm{ppm}$. mesomethylene protons $-\mathrm{CH}_{2}(m)$ - have resonances at 1.9 and $1.45 \mathrm{ppm}$, respectively. racemo-methylene protons $-\mathrm{CH}_{2}(r)$ - reveal the signal at $1.6 \mathrm{ppm}$. The signals of $r$ methylene protons at $1.6 \mathrm{ppm}$ and of the $m$ methylene proton at 1.45 ppm are partially overlapped. That is why the meso-content was measured by comparison of integrals of methine signal at $2.25 \mathrm{ppm}$ and one of meso-resonances at $1.9 \mathrm{ppm}$. This revealed the ratio $r: m=55: 45$ for the PEtA obtained at $35{ }^{\circ} \mathrm{C}$ via SET-DTLRP and $r: m=52: 48$ for PEtA obtained at $35{ }^{\circ} \mathrm{C}$ via free radical polymerization (FRP) at the same temperature.

It is worth to compare these results with those of tacticity measurements obtained by us previously ${ }^{4,6,34}$ for PVC and PLA (Table 2). This reveals some regularities both known before and new ones. (1) The lower polymerization temperature the higher syndioctacticity; (PVC-62\% at $25{ }^{\circ} \mathrm{C}, 60 \%$ at $\left.35{ }^{\circ} \mathrm{C}\right){ }^{4}(2)$ for the same polymerization temperature SET-DTLRP yields polymers with higher syndioctacticity than FRP (PVC-62 vs. $56 \%$ at $25{ }^{\circ} \mathrm{C},{ }^{6} \mathrm{PEtA}-55$ vs. $52 \%$ at $35{ }^{\circ} \mathrm{C}$ ). This observation is important as it illustrates that radical polymerization processes are complex and require thorough mechanism investigations; (3) the longer $n$-alkyl group in a $\operatorname{Poly}(n$ alkyl acrylate) the higher syndiotactic content (SET-DTLRP PLA, $n$-alkyl $=\mathrm{C}_{12} \mathrm{H}_{25}, r=75 \%$ at $35{ }^{\circ} \mathrm{C} ;{ }^{34}$ SET-DTLRP PEtA $n$-alkyl $=\mathrm{C}_{2} \mathrm{H}_{5}$, $r=55 \%$ ). It is interesting to note that chlorine is intermediate in the vinyl substituents between carbethoxy and carbdodecoxy groups. It would be interested to find a poly(alkyl acrylate) with a similar to SET-DTLRP PVC tacticity. This is a goal of our future work to find out how size and electronic effects ( $I$ and $M$ ) can influence vinyl polymer tacticity.

Journal of Polymer Science: Part A: Polymer Chemistry DOI 10.1002/pola 


$$
\begin{aligned}
& \mathrm{Na}_{2} \mathrm{~S}_{2} \mathrm{O}_{4} \stackrel{\text { water }}{\longrightarrow} 2 \mathrm{Na}^{+}+\mathrm{S}_{2} \mathrm{O}_{4}{ }^{2-} \\
& \mathrm{S}_{2} \mathrm{O}_{4}{ }^{2-} \stackrel{\text { interface }}{\rightleftharpoons} 2 \mathrm{SO}_{2}^{\circ-} \\
& \mathrm{CHI}_{3}+\mathrm{SO}_{2}^{\bullet-} \stackrel{\mathrm{SET}}{\longrightarrow} \mathrm{CHI}_{2}^{\bullet}+\mathrm{I}^{-}+\mathrm{SO}_{2}
\end{aligned}
$$

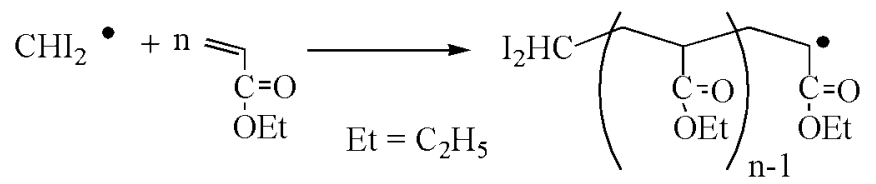

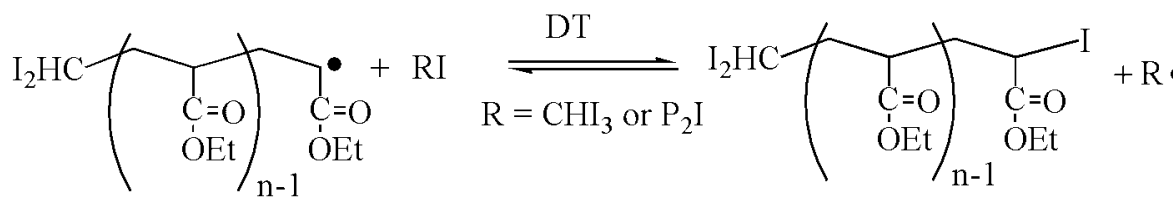

$$
\begin{aligned}
& \mathrm{P}_{1} \overbrace{\mathrm{I}}^{\mathrm{I}}+\mathrm{SO}_{2} \cdot-\stackrel{\mathrm{SET}}{\longrightarrow} \mathrm{P}_{1} \widehat{\mathrm{I}}^{\bullet}+\mathrm{I}-\mathrm{SO}_{2}
\end{aligned}
$$

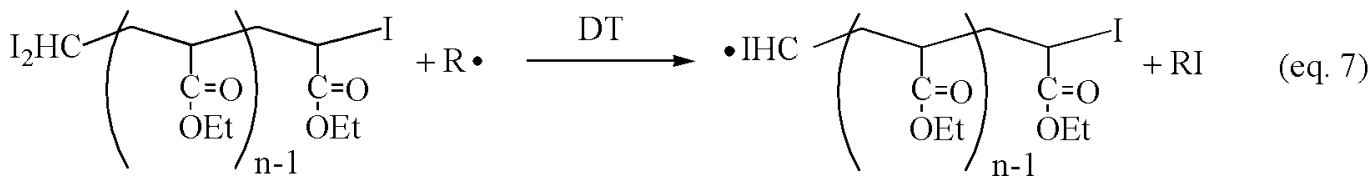

$$
\begin{aligned}
& \text { - IHC }\left(\begin{array}{l}
\mathrm{T}=\mathrm{O} \\
\mathrm{OEt}
\end{array}\right)_{\mathrm{n}}^{\mathrm{I}} \\
& m>\mathrm{C}_{\mathrm{C}}=\mathrm{O} \\
& \stackrel{\substack{\mathrm{C}=\mathrm{O} \\
\stackrel{\mathrm{OE}}{\longrightarrow}}}{\longrightarrow} \\
& \prod_{\substack{\mathrm{C}=\mathrm{O} \\
\mathrm{OEt}}}^{1}\left(\begin{array}{l}
\mathrm{C}=\mathrm{O} \\
\mathrm{OEt}
\end{array} \prod_{\mathrm{m}-1}^{\substack{\mathrm{C}=\mathrm{O} \\
\mathrm{OEt}}}\right)_{\mathrm{n}}^{\mathrm{I}}(\mathrm{eq} .8)
\end{aligned}
$$

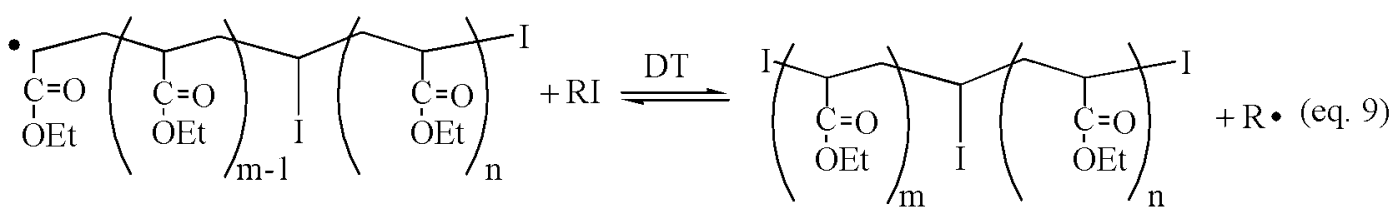

$$
\begin{aligned}
& \mathrm{P}_{1} \overbrace{\mathrm{I}}^{\mathrm{I}}+\mathrm{P}_{2} \bullet \stackrel{\mathrm{DT}}{=} \mathrm{P}_{2} \mathrm{I}+\mathrm{P}_{1} \overbrace{\mathrm{I}}^{\bullet}
\end{aligned}
$$

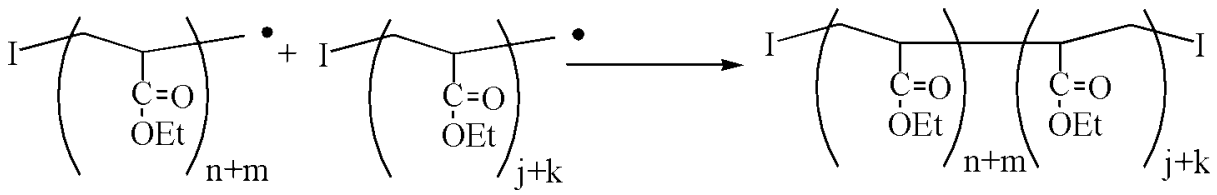

Scheme 1. Simplified Mechanism of SET-DTLRP of EtA in aqueous medium.

\section{Simplified Mechanism}

The NMR and kinetic data are sufficient to allow conclusion that the simplified mechanism describing in the SET-DTLRP ${ }^{4}$ of EtA is pre- sented in Scheme 1 and similar to the one published elsewhere. ${ }^{8}$ The SET-DTLRP provides the reversible activation-deactivation steps required for an LRP mechanism using a combination of 
Table 2. Syndiotactic Content $(r)$ in Different Vinyl Polymers Obtained by SETDTLRP and Free Radical Polymerization (FRP)

\begin{tabular}{ccccccc}
\hline & & \multicolumn{5}{c}{$r$} \\
\cline { 3 - 7 } & & $T$ & SET-DTLRP & FRP-PEtA & SET-DTLRP & SET-DTLRP \\
No. $^{4,6}$ & FRP-PVC $^{6}$ \\
\hline${ }^{\circ}$ C) & PEtA (This Article) & (This Article) & PLA $^{34}$ & PVC $^{4}$ & \\
\hline & 25 & & & & 62 & 56 \\
2 & 35 & 55 & 52 & 75 & 60 & \\
\hline
\end{tabular}

competitive single electron transfer (SET) and degenerative transfer (DT) mechanism. ${ }^{4}$ The iodoform (initiator) is reduced by SET from $\mathrm{SO}_{2}^{--}$radical anion. The latter is formed by the dissociation of $\mathrm{S}_{2} \mathrm{O}_{4}^{2-}$. These steps provide the formation of the initial $\mathrm{CHI}_{2}^{\bullet}$ radical. The other main reaction steps of this mechanism include the propagation, DT to initiator or dormant species, activation of dormant species mediated by radical anion $\mathrm{SO}_{2}^{\cdot-}$ and a possible termination by recombination. The polymer molecules formed by the latter process will be still active as a difunctional macroinitiators as they contain two active $-\mathrm{CHIC}(\mathrm{O})$ $\mathrm{OCH}_{2} \mathrm{CH}_{3}$ chain ends and the functionality of the PEtA remains 2.0. The polyacrylate synthesized by this synthetic method is telechelic $\alpha, \omega$-di(iodo)poly(ethyl acrylate).

\section{Kinetic Studies}

The kinetics experiments described in this publication were carried out in a $50 \mathrm{~mL}$ glass highpressure tube equipped with a magnetic stirring bar. Because of the heterogeneity of the reaction medium the sampling is impossible and each point depicted in the kinetics plots represents a single experiment repeated under the same reactions conditions for a different reaction time.

SET-DTLRP of EtA was carried out in water media containing $\mathrm{NaHCO}_{3}$ as a buffer and was catalyzed by $\mathrm{Na}_{2} \mathrm{~S}_{2} \mathrm{O}_{4}$. The initiator was iodoform that is a bifunctional initiator in $\mathrm{Na}_{2} \mathrm{~S}_{2} \mathrm{O}_{4}$ mediated SET-DTLRP. ${ }^{4}$ This polymerization system proved to be efficient for the polymerization of vinyl chloride, ${ }^{4}$ 2-ethylhexyl acrylate, ${ }^{9}$ tert-butyl acrylate, ${ }^{9}$ butyl acrylate ${ }^{8}$, and lauryl acrylate ${ }^{36}$ as well as block-copolymerization of vinyl chloride and butyl acrylate $\mathrm{e}^{11,23,24}$ in water at room temperature. The C-I-ended dormant species is believed to be labile enough to allow the degener- ative transfer, and the $\mathrm{R}$ (acrylate group) has to stabilize the growing polymer radical through inductive and resonance effects. ${ }^{37}$ In the specific case of ethyl acrylate monomer it is particularly interesting to observe the influence of short ethyl group in the polymerization rate. Moreover, previous experiments concerning the SET-DTLRP of methyl acrylate failed in the preparation of macroinitiators with terminal active chains ends. ${ }^{38}$ On this matter, the synthesis of poly(methyl acrylate) through a living approach was only proposed via iodine transfer by Lacroix-Desmazes. ${ }^{39} \mathrm{~A}$ detailed description of the main reactions involved in the SET-DTLRP was previously published and for that reason is not exposed here. ${ }^{8}$ Unlike other systems based on the DT mechanism, ${ }^{37,40-42}$ in the SET-DTLRP process the activation results also from a single electron transfer between the $\mathrm{SO}_{2}^{--}$radical anion and the active iodine containing compounds. This different approach is more desirable from the chemical standpoint, since contrary to conventional initiators, the compound used (sodium dithionite) to reduce the active chain ends $\left(\mathrm{CHI}_{3},-\mathrm{CHI}_{2}\right.$, $-\mathrm{CHIC}(\mathrm{O}) \mathrm{OEt}$ ) leading to the propagating radicals, does not produce a polymer chain. Control experiments without $\mathrm{CHI}_{3}$ gave no traces of polymer. Therefore, the control over the polymerization and the percentage of active chain ends, related to the total polymer chain ends are enhanced. The conventional peroxide/diazo initiators will always lead to terminal dead chain ends resulting from fragments of the initiator used.

\section{SET-DTLRP of EtA Initiated from $\alpha, \omega$-di(iodo)PEtA: Reinitiation Experiment}

The living character of PEtA macroinitiator prepared by SET-DTLRP was evaluated according to Szwarc's definition of a living polymer. ${ }^{43-45}$ Liv-

Journal of Polymer Science: Part A: Polymer Chemistry DOI 10.1002/pola 


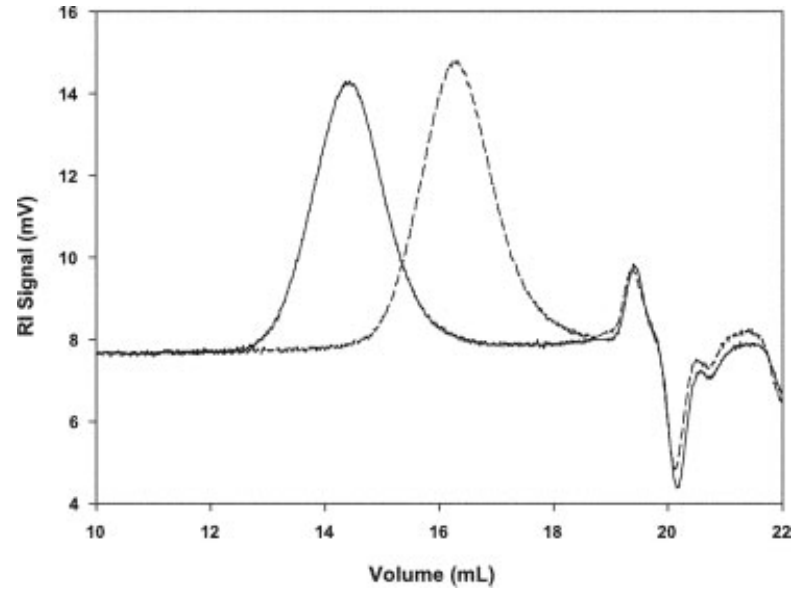

Figure 4. Reinitiation experiment.

ing polymers are the polymers that retain their ability to propagate for a long time and grow to a desired maximum size while their degree of termination or chain transfer is still negligible. Therefore, the living character of PEtA was confirmed by a reinitiation experiment that produced a polymer of $M_{n, \text { TriSEC }}=86,300 \mathrm{Da}$ starting from a purified macroinitiator of $M_{n, \text { TriSEC }}=2,600 \mathrm{Da}$ after $9 \mathrm{~h}$ of reaction at $35{ }^{\circ} \mathrm{C}$ in water (Fig. 4). From Figure 4 it is possible to observe the complete movement of the elution peak toward high molecular weight, which proves the success of the reinitiation experiment.

Figure 5 shows the variation in the $[\eta]$ with the $M_{\mathrm{w}, \text { TriSEC }}$ of the PEtA prepared by SET-DTLRP. The points used in this plot were obtained from different samples prepared at $35{ }^{\circ} \mathrm{C}$. The mathematical relationship between the $[\eta]$ and $M_{\mathrm{w}}$ is:

$$
[\eta]=6.15 \times 10^{-5} M_{\mathrm{w}}^{0.80}
$$

Only a single reference was found concerning the MHS constants of PEtA. The values proposed $\left(K=8.90 \times 10^{-5} \mathrm{dL} / \mathrm{g}\right.$ and $\left.\alpha=0.75\right)$ are different from the obtained in this work.

Figure 6 compares the viscosity of the PEtA prepared by SET and by FRP (based on the $K$ and $\alpha$ constants available in the literature ${ }^{46}$ ).

The results presented in Figure 6 indicate that for same molecular weight the viscosity of the PEtA prepared by SET-DTLRP is higher. Such a difference could be related to the method followed for the determination of the MHS constants, or to the high linearity of the PEtA prepared by LRP approach, due to absence of side reactions. ${ }^{4}$ In this work, it is shown that the SET-DTLRP allows

Journal of Polymer Science: Part A: Polymer Chemistry DOI 10.1002/pola

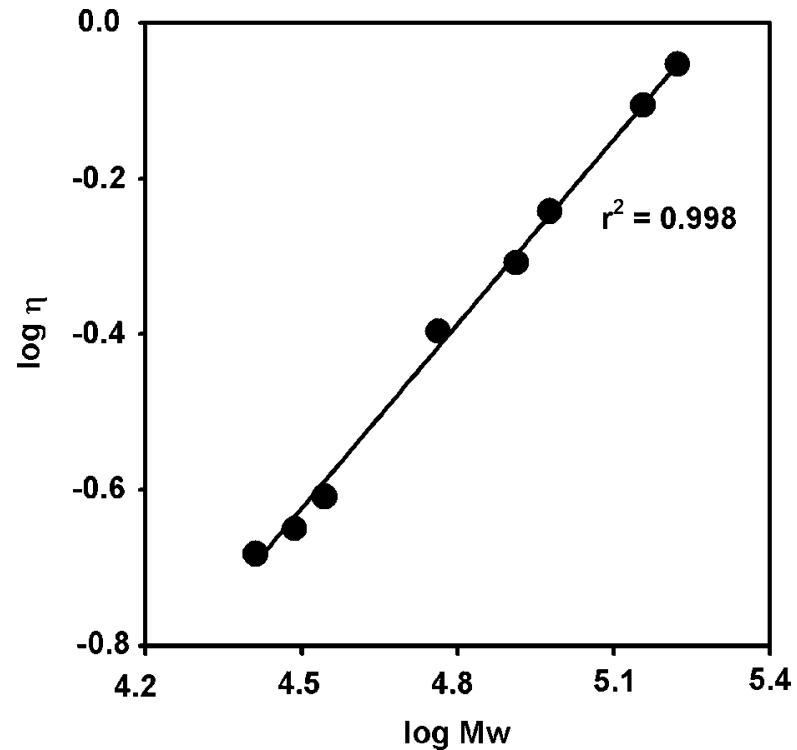

Figure 5. Plot of $\log [\eta]$ versus $\log \left(M_{\mathrm{w}}\right)$ for PEtA prepared by SET/DTLRP at $35{ }^{\circ} \mathrm{C}$ from which the MarkHouwink-Sakurada relationship was derived.

the preparation of the linear macrostructures even in polar solvents (water). Furthermore, the viscosity differences between the PEtA prepared by SET-DTLRP and FRP increase with the molecular weight.

The use of a viscosimeter detector in the TriSEC configuration is extremely useful for the determination of the size of molecules. These val-

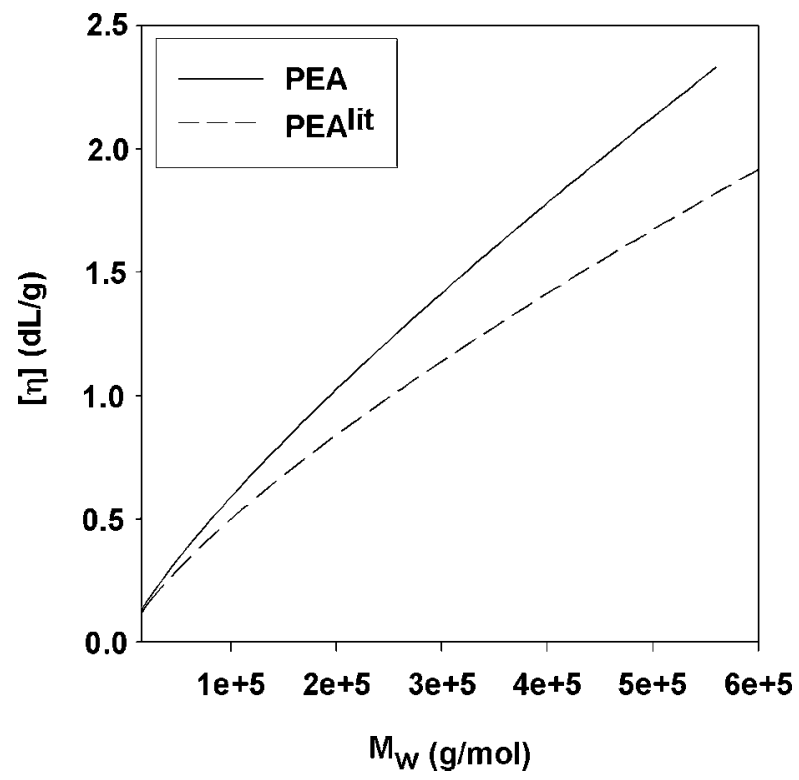

Figure 6. Variation of viscosity with the molecular weight for PEtA prepared by SET-DTLRP and FRP. 
ues can be related to the secondary structure of the polymer, either in terms of chain stiffness, conformation, or branching. Among the advantages that results from the characterization of MWD by SEC with multi detection is the possibility to determine parameters as the gyration ra$\operatorname{dius}\left(R_{\mathrm{g}}\right)_{.}{ }^{47}$

The scaling relationship between the $R_{\mathrm{g}}$ and $M_{\mathrm{w}}$ is presented in Figure 7. The $\log R_{\mathrm{g}}$ versus $\log M_{\mathrm{w}}$ reveals a linear relation along the whole range of $M_{\mathrm{w}}$ analyzed and can be described mathematically by the relation:

$$
R_{g}=6.94 \times 10^{-3} M_{\mathrm{w}}^{0.85}
$$

To the best of our knowledge, there is no reference in the literature data dealing with constants of the $R_{\mathrm{g}}$ versus $M_{\mathrm{w}}$ equation for PEtA.

The glass transition temperature was determined by DMTA and is presented in Figure 8. The DMTA has been intensely used and recognized as a powerful tool to identify the materials thermal transition due to its extremely high sensibility. Its special sensibility to determine frequency dependent transition, as the glass transition temperature that represents the motions of long chain segments is of outstanding importance. The basic function of a DMTA is to obtain information about the mechanical and thermal properties of the materials by applying a sinusoidal load to a specimen and measuring

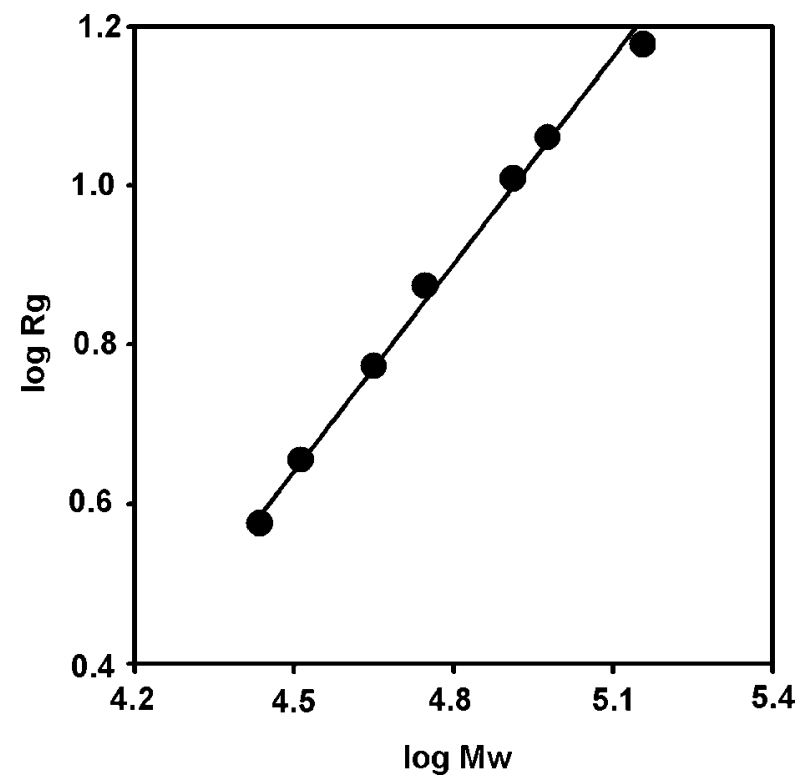

Figure 7. Plot of $\log R_{\mathrm{g}}$ versus $\log M_{\mathrm{w}, \text { TriSEC }}$ PEtA prepared by SET/DTLRP at $35{ }^{\circ} \mathrm{C}$.

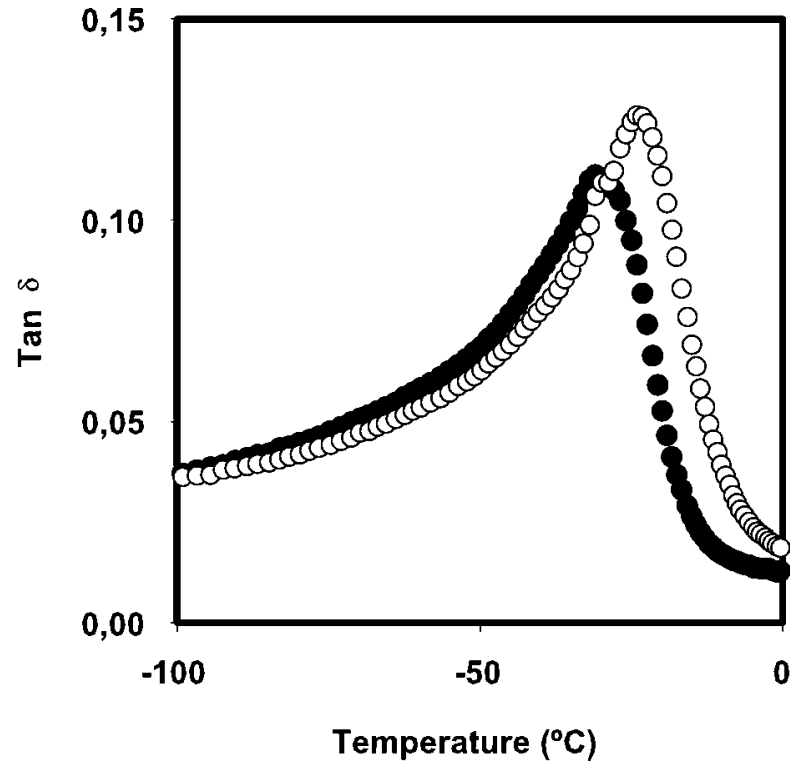

Figure 8. DMTA trace of PEtA prepared at $35{ }^{\circ} \mathrm{C}$ $\left(M_{n, \text { TriSEC }}=23,480 \mathrm{Da}, M_{\mathrm{w}} / M_{n}=2.1\right):(\circlearrowleft) 1 \mathrm{~Hz}$ and $10 \mathrm{~Hz}(\bigcirc)$.

the resultant deformation, while the sample is subjected to a controlled temperature programme.

The DMTA was carried out in the Constrain Layer Damping Mode, which was previously used by the authors for different materials with success. $^{8,11,48}$

Figure 8 shows a peak of $\tan \delta(1 \mathrm{~Hz})$ at $-25{ }^{\circ} \mathrm{C}$ that is sensitive to the frequency, and for that reason can be ascribed to the glass transition temperature. The value achieved fairly matches some other reported results. ${ }^{13,16}$

\section{CONCLUSION}

The results presented in this work show the possibility of using the SET-DTLRP method with all the advantages amply described in the literature ${ }^{4,8,11,23,24,26}$ to an hydrophobic monomer in a polar solvent. The results presented in this work are of extreme importance considering the expected low steric stabilization resonance given by the ethyl side chain. Nevertheless, the SET-DTLRP allowed the polymerization of EtA with terminal active chains ends that were successfully reinitiated. A relatively low syndiotacticity content of $55 \%$ witnesses that a carbethoxy group provides almost no stereospecificity of the polymerization process. As main conclu- 
sion, this approach allows the synthesis of $\alpha, \omega$ di(iodo)PEtA segments that can be further functionalized or used in synthesis of complex architectures. This possibility is even more important, since the short ester side chains of PEtA are known to provide an enhanced polymerpolymer interaction with other materials for example poly(vinyl chloride). ${ }^{49}$

\section{REFERENCES AND NOTES}

1. Perrier, S.; Takolpuckdee, P. J Polym Sci Part A: Polym Chem 2005, 43, 5347-5393.

2. Farcet, C.; Charleux, B.; Pirri, R. Macromolecules 2001, 34, 3823-3826.

3. Kamigaito, M.; Ando, T.; Sawamoto, M. Chem Rev 2001, 101, 3689-3745.

4. Percec, V.; Popov, A. V.; Ramirez-Castilho, E.; Coelho, J. F. J.; Hinojosa-Falcon, L. A. J Polym Sci Part A: Polym Chem 2004, 42, 6267-6282.

5. Percec, V.; Popov, A. V.; Ramirez-Castillo, E.; Monteiro, M.; Barboiu, B.; Weichold, O.; Asandei, A. D.; Mitchell, C. M. J Am Chem Soc 2002, 124, 49404941.

6. Percec, V.; Popov, A. V.; Ramirez-Castillo, E.; Weichold, O. J Polym Sci Part A: Polym Chem 2003, 41, 3283-3299.

7. Percec, V.; Guliashvili, T.; Popov, A. V. J Polym Sci Part A: Polym Chem 2005, 43, 1948-1954.

8. Coelho, J. F. J.; Silva, A. M. F. P.; Popov, A. V.; Percec, V.; Abreu, M. V.; Gonçalves, P. M. O. F.; Gil, M. H. J Polym Sci Part A: Polym Chem 2006, 44, 2809-2825.

9. Percec, V.; Ramirez-Castilho, E.; Popov, A. V.; Hinojosa-Falcon, L. A.; Guliashvili, T. J Polym Sci Part A: Polym Chem 2005, 43, 2178-2184.

10. Percec, V.; Popov, A. V.; Ramirez-Castilho, E.; Weichold, O. J Polym Sci Part A: Polym Chem 2004, 42, 6364-6374.

11. Coelho, J. F. J.; Silva, A. M. F. P.; Popov, A. V.; Percec, V.; Abreu, M. V.; Gonçalves, P. M. O. F.; Gil, M. H. J Polym Sci Part A: Polym Chem 2006, 44, 3001-3008.

12. Chakrabarti, R.; Das, M.; Chakraborty, D. J Appl Polym Sci 2004, 93, 2721-2730.

13. Princi, E.; Vicini, S.; Pedemonte, E.; Arrighi, V.; McEwen, I. J Appl Polym Sci 2007, 103, 90-99.

14. Chakrabarti, R.; Chakraborty, D. J Appl Polym Sci 2006, 102, 3698-3703.

15. Salmeron Sanchez, M.; Brigido Diego, R.; Iannazzo, S. A. M.; Gomez Ribelles, J. L.; Monleon Pradas, M. Polymer 2004, 45, 2349-2355.

16. Ivan, B.; Almdal, K.; Mortensen, K.; Johannsen, I.; Kops, J. Macromolecules 2001, 34, 1579-1585.

Journal of Polymer Science: Part A: Polymer Chemistry DOI 10.1002/pola
17. Wu, Y.; Shi, Y.; Fu, Z. Polymer 2005, 46, 1272212728.

18. Shi, Y.; Fu, Z.; Li, B.; Yang, W. J Polym Sci Part A: Polym Chem 2006, 44, 2468-2475.

19. Jianying, H.; Jiayan, C.; Jiaming, Z.; Yihong, C.; Lizong, D.; Yousi, Z. J Appl Polym Sci 2006, 100, 3531-3535.

20. Andreozzi, L.; Faetti, M.; Giordano, M.; Hvala, M.; Galli, G.; Laus, M. Mol Cryst Liq Cryst Sci Technol Sect A 2002, 372, 229-239.

21. Xia, J.; Matyjaszewski, K. Macromolecules 1997, 30, 7697-7700.

22. Coelho, M. R. G.; San Gil, R. A. S.; Tavares, M. I. B. Polym Test 1996, 15, 485-490.

23. Coelho, J. F. J.; Carreira, M.; Popov, A. V.; Gonçalves, P. M. O. F.; Gil, M. H. J Vinyl Addit Technol 2006, 12, 156-165.

24. Coelho, J. F. J.; Carreira, M.; Popov, A. V.; Gonçalves, P. M. O. F.; Gil, M. H. Eur Polym J 2006, 42, 2313-2319.

25. Tabuchi, M.; Kawauchi, T.; Kitayama, T.; Hatada, K. Polymer 2002, 43, 7185-7190.

26. Coelho, J. F. J. New Technologies for Homopolymerization and Copolymerization of Vinyl Chloride, $\mathrm{PhD}$ Thesis; University of Coimbra: Coimbra, 2006.

27. Li, P.; Qiu, K.-Y. J Polym Sci Part A: PolymChem 2002, 40, 2093-2097.

28. Hsieh, H. L.; Quirk, R. P. Anionic Polymerization Principles and Practical Applications; Marcel Dekker: New York, 1996.

29. Matyjaszewski, K.; Gaynor, S.; Wang, J.-S. Macromolecules 1995, 28, 2093-2095.

30. Qiu, J.; Charleux, B.; Matyjaszewski, K. Prog Polym Sci 2001, 26, 2083-2134.

31. Yamada, B.; Zetterlund, P. B. In Handbook of Radical Chemistry; Matyjaszewski, K.; Davis, T. P., Eds.; Wiley: New York, 2002; pp 117186.

32. Boyer, C.; Valade, D.; Lacroix-Desmazes, P.; Ameduri, B.; Boutevin, B. J Polym Sci Part A: Polym Chem 2006, 44, 5763-5777.

33. Valade, D.; Boyer, C.; Ameduri, B.; Boutevin, B. Macromolecules 2006, 39, 8639-8651.

34. Percec, V.; Grigoras, C.; Kim, H.-J. J Polym Sci Part A: Polym Chem 2004, 42, 505-513.

35. Percec, V.; Guliashvili, T.; Ladislaw, J. S.; Wistrand, A.; Stjerndahl, A.; Sienkowska, M. J.; Monteiro, M. J.; Sahoo, S. J Am Chem Soc 2006, 128, 14156-14165.

36. Coelho, J. F. J.; Carvalho, E. Y.; Marques, D. S.; Popov, A. V.; Goncalves, P. M.; Gil, M. H. Macromol Chem Phys 2007, 208, 1218-1227.

37. Iovu, M. C.; Matyjaszewski, K. Macromolecules 2003, 36, 9346-9354.

38. Coelho, J. F. J.; Gonçalves, P. M. O. F.; Gil, M. H. Unpublished work, 2005.

39. Lacroix-Desmazes, P.; Severac, R.; Boutevin, B. Macromolecules 2005, 38, 6299-6309. 
40. Gaynor, S. G.; Wang, J.-S.; Matyjaszewski, K. Macromolecules 1995, 28, 8051-8056.

41. Goto, A.; Ohno, K.; Fukuda, T. Macromolecules 1998, 31, 2809-2814.

42. Lansalot, M.; Farcet, C.; Charleux, B.; Vairon, J.-P.; Pirri, R. Macromolecules 1999, 32, 7354-7360.

43. Szwarc, M. J Polym Sci Part A: Polym Chem 1998, $36, \mathrm{ix}-\mathrm{xv}$.

44. Szwarc, M.; Levy, M.; Milkovich, R. J Am Chem Soc 1956, 78, 2656-2657.
45. Szwarc, M. Nature 1956, 178, 1168.

46. Polymer Handbook; Brandrup, J.; Immergut, E. H., Eds.; Wiley: New York, 1989.

47. Coelho, J. F. J.; Gonçalves, P. M. F. O.; Miranda, D.; Gil, M. H. Eur Polym J 2006, 42, 751-763.

48. dos Santos, K. S. C. R.; Coelho, J. F. J.; Ferreira, P.; Pinto, I.; Lorenzetti, S. G.; Ferreira, E. I.; Higa, O. Z.; Gil, M. H. Int J Pharm 2006, 310, 37-45.

49. Walsh, D. J.; McKeown, J. G. Polymer 1980, 21, 1335-1340. 